\title{
Can social capital contribute to the improvement of oral health?
}

\section{Patricia Maria Zarzar ${ }^{(a)}$ Efigênia Ferreira e Ferreira ${ }^{(b)}$ Ichiro Kawachi(c)}

\footnotetext{
(a) Departament of Pediatric Dentistry and Orthodontics, School of Dentistry, Univ Federal de Minas Gerais - UFMG, Belo Horizonte, MG, Brazil.
}

(b) Departament of Oral Public Health, School of Dentistry, Univ Federal de Minas Gerais UFMG, Belo Horizonte, MG, Brazil.

(c) Department of Society, Human Development, and Health, Harvard School of Public Health, Boston, MA, USA. ncreasing evidence suggests that a broad range of social determinants, not only biological risk factors and individual lifestyle, influence the general health of people. Recent studies ${ }^{1-3}$ have revealed that social determinants, among the latter of which is social capital, have an important influence on health. Émile Durkheim, in late nineteenth century, was the first researcher to suggest links between individual health and social cohesion in his study of suicide. Studies reveal that people in society with higher levels of social capital live longer, have lower premature mortality rates, are less violent and have lower levels of self-perception of poor health.-6

Social capital is defined as a variety of different entities having two characteristics in common: they all consist of some aspect of social structure, and they facilitate certain actions of individuals who are within the structure. ${ }^{7}$ Social capital refers to "features of social organization, such as trust, norms and networks that can improve the efficacy of society by facilitating coordinated actions". ${ }^{8}$ We could argue that because people are embedded and socialized in networks, network members' resources either empower or constrain people's choice of health-related behavior options. Social relationship with embedded resources can be expected to be beneficial (and occasionally harmful) to both individuals and collective members of these networks.

Previous studies have demonstrated an association between neighborhood social capital and oral health., ${ }^{9}, 10$ A Brazilian study found that higher levels of community empowerment, one domain of social capital, was associated with lowered risk of dental injuries, ${ }^{9}$ as well as dental caries, ${ }^{10}$ while another study ${ }^{11}$ in Japanese children showed protective contextual effects of social cohesion on dental caries. These results represent actions taken by neighbors to improve their neighborhood. Those actions require communities to have and realize collective, as opposed to individual goals. Another example is a study ${ }^{12}$ conducted in Japanese adolescents that demonstrated that higher levels of neighborhood trust and vertical social capital in school were associated with better oral health. Higher levels of social support, social trust, civic participation and also interpersonal associations are factors that influenced the best self-rated health as demonstrated in another Brazilian study. ${ }^{2}$ This suggests that some elements of social capital can play an important role in protecting the health of children, adolescents and adults living in a context of a country where inequalities have been a reality. Therefore, Dentistry should be directed to distal factors, such as social capital, to gain a better understanding of oral health being linked to social determinants, as well as recognizing that social capital can be an important tool in the implementation of more effective public health policies. 


\section{References}

1. Giordano GN, Lindstrom M. The impact of changes in different aspects of social capital and material conditions on self-rated over time: a longitudinal cohort study. Soc Sci Med. 2010 Mar;70(5):700-10.

2. Borges CM, Campos AC, Vargas AD, Ferreira EF, Kawachi I. Social capital and self-rated health among adolescents in Brazil: an exploratory study. BMC Res Notes. 2010 Dec 16;3:338. doi: 10.1186/1756-0500-3-338.

3. Iwase T, Suzuki E, Fujiwara T, Takao S, Doi H, Kawachi I. Do bonding and bridging social capital have differential effects on self-rated health? A community based study in Japan. J Epidemiol Community Health. 2012 Jun;66(6):557-62.

4. Kawachi I, Kennedy BP, Lochner K, Prothrow-Stith D. Social capital, income inequality, and mortality. Am J Public Health. 1997 Sep;87(9):1491-8.

5. Kawachi I, Kim D, Coutts A, Subramanian SV. Commentary: Reconciling the three accounts of social capital. Int J Epidemiol. 2004 Aug;33(4):682-90.

6. Fujiwara T, Kawachi I. Social capital and health. A study of adult twins in the U.S. Am J Prev Med. 2008 Aug;35(2):139-44.
7. Coleman JS. Social Capital in the Creation of Human Capital. Am J Sociol. 1988;S95-120.

8. Putman RD. The prosperous community: social capital and public life. Am Prospect. 1993;4(13):35-42.

9. Patussi MP, Hardy R, Sheiham A. Neighborhood social capital and dental injuries in Brazilian adolescents. Am J Public Health. 2006 Aug;96(8):1462-8.

10. Patussi MP, Hardy R, Sheiham A. The potential impact of neighborhood empowerment on dental caries among adolescents. Community Dent Oral Epidemiol. 2006 Oct;34(5):34450.

11. Aida J, Ando Y, Oosaka M, Niimi K, Morita M. Contributions of social context to inequality in dental caries: a multilevel analysis of Japanese 3-year-old children. Community Dent Oral Epidemiol. 2008 Apr;36(2):149-56.

12. Furuta M, Ekuni D, Takao S, Suzuki E, Morita M, Kawachi I. Social capital and self-rated oral health among young people. Community Dent Oral Epidemiol. 2012 Apr;40(2):97-104. 